\title{
LA COMISIÓN NACIONAL DE COLONIZACIÓN Y LA EXPANSIÓN DE LA PEQUEÑA PROPIEDAD RURAL EN MÉXICO 1947-1963¹
}

\author{
Luis Aboites Aguilar \\ El Colegio de México
}

Colo trabajo revisa la corta vida de la Comisión Nacional de
que ha llamado muy poco la atención de la historiografía dedi-
cada a la cuestión agraria del siglo xx en México. Se intentará
mostrar que la cNC es útil para conocer el lugar que ocupó una
postura que bien podría calificarse de liberal en relación con
el problema agrario, uno de los principales componentes de la
revolución mexicana de 1910. Esa postura inspiró propuestas
que se sumaron a otras que por igual buscaban acabar con el lati-
fundismo y dar tierras a las mayorías desposeídas. Sin embargo,
el liberalismo agrario, por así llamarlo, no comulgaba ni con la
restitución ni con la dotación de ejidos. Su apuesta era fraccionar Fecha de recepción: 7 de julio de 2017

Fecha de aceptación: 29 de noviembre de 2017

\footnotetext{
1 Agradezco a la historiadora Andrea Ibarra su apoyo en la consulta de archivos y búsquedas bibliográficas, así como su lectura crítica de un borrador; y a Gabriela Torres-Mazuera, por la invitación yucateca de noviembre de 2016 que propició este texto. El trabajo de los dictaminadores ha sido impecable e implacable. Quedo profundamente agradecido con ellos.
} 
la gran propiedad rural y formar una clase de auténticos pequeños propietarios, esto es, hacer realidad el sueño decimonónico. Tal era la bandera de diversos grupos y personajes involucrados en el movimiento revolucionario. "Mayor número de propietarios -sostenía Wistano Luis Orozco en 1911- significa mayor número de hombres felices". ${ }^{2}$ Para lograrlo, algunos insistieron en el viejo proyecto de la colonización, del que la CNC es un eslabón. Este trabajo trata de situar precisamente el papel de la colonización y de la CNC en la resolución del problema agrario surgido de la revolución de 1910, y su relación con la expansión de la pequeña propiedad rural durante el siglo xx.

Ha sido tan abrumadora la atención dada a los ejidos posrevolucionarios y a su relación con la política agraria que el liberalismo, la pequeña propiedad y la colonización misma han quedado fuera de foco. Ejemplo de ello es que en el conocido libro de Mendieta y Núñez la colonización aparece al final, como parte de las "políticas complementarias" del reparto agrario. ${ }^{3}$ Es probable incluso que alguien se entere de la existencia de la $\mathrm{CNC}$ al momento de leer estas líneas.

En este artículo se argumenta también que acercarse a la CNC facilita la tarea de buscar un modo distinto de hacer estudios de historia agraria mexicana del siglo xx. Distinto porque pretende alejarse lo más posible del énfasis otorgado al Estado y a la reforma agraria (entendida como reparto ejidal), lo mismo que a la legislación y al gasto gubernamental. Más que el análisis del Estado y de sus políticas e instituciones, se propone centrar la atención en los propietarios privados y, por supuesto, en su contraparte inseparable: los trabajadores agrícolas. Así, dicha de manera general, la propuesta es empezar por la relación capitaltrabajo, avanzar en su conocimiento y luego situar el quehacer

2 En Silva Herzog, La cuestión, I, p. 200.

3 Véase su obra Mendieta y NúÑEZ, El problema, pp. 453-471. 
del Estado en esa relación. Se trata de una investigación en marcha, que apenas da sus primeros pasos.

No es remoto que este propósito genere escepticismo, si no es que sorna. De entrada, podrá preguntarse cómo intentar alejarse del Estado si se empieza estudiando una institución estatal. Tampoco es remoto que se diga que no hay que perder el tiempo ya que la única y verdadera CNC es la criatura de origen cardenista, la Confederación Nacional Campesina (1938), y que es ésa la que realmente importa. Tan importa que sigue viva después de 78 años. En cambio, la CNC no solo murió en su adolescencia, sino que lleva muerta más de medio siglo. "Tan joven y tan muerta”, podría decirse de ella, parafraseando a María Luisa $L a$ China Mendoza. ${ }^{4}$

Conviene aclarar lo que se entiende por colonización, un elemento clave en el argumento de este trabajo. Una noción general hace referencia a un movimiento de población promovido por el Estado con el objetivo de impulsar la ocupación de determinadas zonas del territorio caracterizadas por la combinación de una población escasa y terrenos considerados vacíos o muy poco explotados. Por todo ello, es opuesto a poblamiento, cuya característica primordial es que corresponde a los movimientos espontáneos de la sociedad, no planeados y menos organizados por el poder público. Con mayor precisión, poblamiento se refiere al fenómeno general de la ocupación y distribución de la población en un territorio determinado, y la colonización así

\footnotetext{
${ }^{4}$ Algo sugiere el hecho de que la CNC no goce de las simpatías de algunos autores vinculados a la reforma agraria o al estudio del agrarismo. No se la menciona en las extensas memorias (900 pp.) de un alto funcionario del ramo, salvo por una referencia a la ley de 1963 que la extinguió. Véase Gómez VIllanueva, El campo, p. 631. Tampoco la menciona Jesús Silva Herzog en su obra El agrarismo, de 1959. En cambio, los expertos en derecho agrario generalmente sí la toman en cuenta, al menos Ruiz Massieu, Temas, e Ibarrola, Derecho agrario. Otros estudios que hacen referencia al organismo son los de Mendieta y Núñez, El problema agrario; Reyes Osorio, Stavenhagen, ECKSTEIN y Ballesteros, Estructura, y Medin, El sexenio.
} 
entendida es apenas una de sus modalidades. ${ }^{5}$ No es lo mismo el Bajío que el distrito de riego del Bajo Bravo, como tampoco es lo mismo un mineral que un presidio, o una estación ferroviaria que con el tiempo se transforma en una localidad urbana como Empalme, Sonora, que Ciudad Alemán, la ciudad fallida que debía ser la cabecera del movimiento económico provocado por la labor de la Comisión del Papaloapan (1947). Más adelante se mostrarán los atributos que fue adquiriendo la colonización en las distintas épocas mexicanas, en particular en dos de ellas: los extranjeros en el siglo xIx, y en el siglo xx como vía de cambio agrario distinta al reparto ejidal.

El trabajo tiene cuatro apartados. El primero da pormenores de la breve trayectoria de la institución; en el segundo se intenta situar el objeto de la CNC en relación con las antiguas y no tan antiguas ideas y experiencias de lo que en general se denomina “colonización” y el lugar de la pequeña propiedad rural en ella; en el tercer apartado se reúnen algunos de los principales argumentos que explican la rápida desaparición de la comisión gubernamental. Se verá que muy pocos la defendieron. Y por último, en las conclusiones se exponen ideas sobre cómo la CNC ayuda a armar una perspectiva distinta en torno al cambio agrario en México durante el siglo xx.

\section{NACE EN 1947}

La CNC nació en una época en que por diversas vías el Estado mexicano trataba de impulsar la economía nacional favoreciendo a las empresas privadas. En vista de la pobreza de la hacienda pública, pese al aumento de la recaudación del impuesto sobre la renta logrado en 1942-1944, parecía como si el Estado, en lugar de otorgar estímulos económicos, como ocurría en otros países,

\footnotetext{
5 Sobre la distinción entre poblamiento y colonización, véase AbOITEs AGUILAR, Norte precario, pp. 273-279.
} 
no tuviera más opción que impulsar cambios legislativos. Este escenario se palpaba en relación con el campo, una de las prioridades del nuevo gobierno del presidente Miguel Alemán (19461952). En su discurso inaugural, el presidente argumentaba:

Podemos lograr una gran producción agrícola aplicando a la explotación de la tierra el esfuerzo de nuestro trabajo, los recursos de la técnica y el régimen legal que garantice por igual al ejido, a la pequeña propiedad y a la propiedad ganadera. Protegeremos estas tres formas de propiedad rural, imponiendo por todos los medios legales la tranquilidad en el campo [...] Mediante una política de colonización bien planeada y que desde luego iniciaremos, se abrirán nuevas tierras al cultivo en donde todos los mexicanos que lo deseen podrán contribuir con su esfuerzo, estimulado por el Estado para aumentar la producción fincando sobre la tierra misma la grandeza de la República. En esta forma también se podrá resolver el problema de la sobrepoblación campesina de algunas regiones del país y aun habrá lugar para que los compatriotas nuestros que han salido fuera $[s i c]$ del país puedan regresar a su patria. ${ }^{6}$

El escaso dinero de la nación tenía además una prioridad indiscutida: la construcción de obras de riego. Si no había más dinero, el gobierno de Alemán recurriría a otro tipo de apoyos, entre ellos el reforzamiento de las garantías político-jurídicas a los propietarios. Y este espaldarazo no era cosa menor. Dos reformas al artículo 27 constitucional, aprobadas a fines de 1946, exhibían la voluntad gubernamental: por un lado, la ampliación de la pequeña propiedad y por tanto de las superficies inafectables; y por otro, la reposición del amparo agrario. ${ }^{7}$ Si el Estado era pobre, el capital privado tenía que hacerse cargo de

${ }^{6} D D D$ (véanse las siglas en la bibliografía), domingo 1o de diciembre de 1946. 7 El amparo en materia agraria había sido derogado por una reforma constitucional de 1933. Véase la nueva fracción XIV del artículo 27 constitucional en DOF (miércoles 10 ene. 1934). 
la economía del país, en este caso de la economía rural. La ley que hizo nacer a la CNC, así como la nueva ley de colonización, formaban parte de este esfuerzo general.

La iniciativa presidencial referida a la creación de la CNC avanzó rápido: la Cámara de Diputados la recibió el 10 de diciembre de 1946, y tres días después el dictamen favorable estaba listo; el día 17 los diputados la aprobaron (por unanimidad de 91 votos) y la enviaron a la Cámara de Senadores. Ésta modificó el primer artículo, pero el 30 de diciembre siguiente la Cámara de Diputados aprobó en definitiva la ley, incluyendo la modificación introducida por el Senado (que se comentará más adelante). Entró en vigor a fines de enero de 1947, junto con la nueva ley de colonización. ${ }^{8}$ Así, en menos de dos meses la labor que antes realizaba una modesta Dirección de Población Rural, Terrenos Nacionales y Colonización, de la Secretaría de Agricultura y Fomento (en apego a la ley del ramo de 1926), pasaba a manos de una institución con mayores facultades, de mayor rango burocrático y presupuesto. ${ }^{9}$ No era el Departamento Agrario, pero quizá pretendía competir con él. ${ }^{10}$

La nueva CNC nació dependiente de la Secretaría de Agricultura y Ganadería (sAG en adelante); por ello el secretario de Agricultura era su presidente. En ese tiempo tal funcionario era el coahuilense Nazario Ortiz Garza, expresidente municipal de

${ }^{8}$ La iniciativa presidencial, de 4 de diciembre de 1946, en AGN, $M A$, c. 569, exp. 545.22/1; y en $D D D$ (miércoles 10 dic. 1946); las leyes de creación de la CNC y de colonización, en $D O F$ (sábado 25 ene. 1947). También se publicaron en un librito. Véase Leyes.

9 AGN, MA, c. 569, exp.545.22/19: memorándum de 10 de marzo de 1947, sobre la "Situación que guarda la Comisión Nacional de Colonización", suscrito por los directivos del nuevo organismo: Luis L. León y Francisco L. Serrano (zona norte), y José López de Llergo y Carlos Chico Alatorre (zona sur).

${ }^{10}$ En DDD (lunes 30 dic. 1946) se lee que el presupuesto del Departamento Agrario para 1947 alcanzaba 12.8 millones de pesos, mientras que el de la CNC para ese mismo año era de 4.4 millones, según el documento citado en la nota anterior. 
Torreón, exgobernador de su estado y empresario vitivinícola en Aguascalientes desde 1947. ${ }^{11}$ Una característica llamativa de la nueva institución era su organización administrativa, basada en una drástica división geográfica: el norte y el sur del país. Esa división fue agregada justamente por los senadores, junto con otra más: en lugar de una sola directiva, compuesta por un vocal ejecutivo y un vocal secretario, como se lee en la iniciativa presidencial y en el dictamen inicial de los diputados, el Senado duplicó el tamaño de la directiva al crear dos vocales ejecutivos y dos vocales secretarios, "uno para la zona norte y otro para la zona sur". ${ }^{12}$ Ignoro si alguna otra dependencia federal de esos años empleaba un criterio geográfico similar. Da la impresión, aunque por ahora no pueda demostrarse, que esa forma de organización administrativa no era simple casualidad o capricho. Por lo pronto sugiere la necesidad de hacer una consideración fina sobre la geografía histórica desde el punto de vista de la propiedad rural. ${ }^{13}$ Los cuatro vocales serían nombrados por el presidente de la República.

11 Martínez Delgado, La experiencia urbana, pp. 310-312.

12 Se ignora el lindero entre las dos zonas. Pero en peleonero memorándum, el vocal secretario de la zona sur lamentaba que los estados de Colima, Guanajuato, Jalisco, Querétaro y Michoacán, todos con mayor infraestructura, hubieran sido asignados a la zona norte. AGN, $M A$, c. 569, exp. 545.22/1, memorándum confidencial de 3 de julio de 1947, de Carlos Chico Alatorre.

${ }_{13}$ Dicha división geográfica lleva a preguntarse si acaso el norte y el sur del país eran percibidos como distintos en cuanto a las labores de colonización y, en esa medida, distintos en cuanto a las posibilidades de expansión de la propiedad privada rural y de redistribución de la población. Desahogar tal pregunta rebasa el alcance de este trabajo. Además, no debe olvidarse que después de la segunda guerra mundial creció el interés por las zonas tropicales en buena parte del planeta. Indicio de ese interés en México es la creación de las comisiones de cuenca, empezando por la del Papaloapan en 1947 y la del Grijalva cuatro años después. Al respecto, véase Poleman, The Papaloapan Project, pp. 3-9; Nelson, The Development, p. 35, y Aвoites Aguilar, “Optimismo", pp. 124-132. En el memorándum de 3 de julio de 1947 citado en la nota anterior, aparece la queja de que la zona norte no hacía otra cosa que 
Uno de los nombramientos presidenciales ilustra bien el rumbo general. Al iniciar sus actividades, y por recomendación del expresidente Abelardo Rodríguez, Luis L. León quedó al frente de la zona norte. Ingeniero agrónomo chihuahuense, León había sido secretario de Agricultura y Fomento en el gabinete del presidente Plutarco Elías Calles (1924-1928) y más tarde, una vez sofocada la rebelión escobarista de 1929, gobernador de su estado. También había sido empleado del gobierno sonorense cuando el general Rodríguez fungía como gobernador (19431948)..$^{14}$ Como tratará de mostrarse, la presencia de León no era casualidad; debe leerse como vínculo con un antecedente fundamental en materia de colonización, referido a la política de irrigación iniciada en 1926.

La nueva ley declaraba de utilidad pública la colonización de la propiedad rural, tanto nacional como privada. ${ }^{15} \mathrm{La}$ cuestión del poblamiento aparecía al señalarse que se pretendía asegurar "el establecimiento normal de nuevos centros de población y el incremento de la producción agrícola y ganadera". Pero lo más importante se hallaba en los artículos quinto y sexto de la ley, que reflejaban bien el contexto del siglo xx. En el quinto se establecía que tanto la CNC como los particulares o sociedades mexicanas podían llevar a cabo la colonización, y que podría

administrar la colonización de los distritos de riego, mientras que la zona sur se había tomado el trabajo de reconocer el terreno para iniciar la formación de colonias en una superficie de 50000 hectáreas.

${ }^{14}$ León fue leal callista a lo largo de su vida. De ese rasgo habla el hecho de que fue uno de los pasajeros del avión que por instrucciones presidenciales llevó al antiguo jefe máximo Calles al exilio en abril de 1936. León regresó al país a fines de 1938, mientras que Calles lo hizo en marzo de 1941. Sobre León, véase Almada, Gobernadores, pp. 571-573, y su propia Crónica, pp. 423-424 y 429. 15 En el dictamen de los diputados de 13 de diciembre de 1946 mencionado antes se lee que la extensión de los terrenos nacionales era de "alrededor" de 3.5 millones de hectáreas. En 1961 se informaba que se tenían localizadas siete millones de hectáreas de "terrenos baldíos, nacionales y demasías". Véase Departamento de Asuntos Agrarios y Colonización, Memoria 1960-1961, s/p. 
"iniciarse de oficio o a petición del presunto empresario". Se ratificaba así la posibilidad privada de fraccionar latifundios, prevista en la ley de colonización de 1926. Pero no era todo. El artículo sexto contenía lo que sin duda era el meollo de este esfuerzo gubernamental, a saber: que los terrenos involucrados en los proyectos de colonización "serán ejidalmente inafectables por un plazo de cinco años, transcurridos los cuales, perderán su inafectabilidad los terrenos que no hayan sido colonizados". Tal previsión era nueva, al menos no aparecía en la ley de 1926. Era el punto de encuentro, antagónico por lo demás, de dos de las vías de cambio agrario surgidas de la revolución de 1910.16

¿Por qué esa nueva protección a la clase propietaria? Porque el agrarismo-ejidalista, por llamarle de algún modo, interfería con la meta gubernamental de otorgar "grandes facilidades al capital privado para tener una inversión segura en la formación de nuevas colonias". ${ }^{17}$ Como todo negocio, el de formar colonias requería garantías, y una de ellas, vital en el México posrevolucionario, era ponerlo a salvo de sí mismo, en este caso de la demanda agraria. No había sorpresa. Con esa misma lógica había procedido el presidente Lázaro Cárdenas al crear los certificados de inafectabilidad ganadera en marzo 1937 y más tarde los de inafectabilidad agrícola. ${ }^{18}$ Los artículos 18 y 22

\footnotetext{
${ }^{16}$ Esta contradicción entre el reparto ejidal y la colonización aparecía en una adición al reglamento agrario de junio de 1923, que declaraba exceptuadas de la dotación de ejidos "las tierras comprendidas en los contratos de colonización celebrados con el gobierno federal”. En Escárcega López y Caraveo Caraveo, Inafectabilidad, p. 64.

17 Así se lee en el dictamen favorable de los diputados a la iniciativa presidencial de crear la CNC. Véase $D D D$ (viernes 13 dic. 1946).

18 Sobre la creación de los certificados ganaderos y más tarde, en octubre de 1940, de los certificados equivalentes para predios agrícolas, véase EsCÁrCEGA López y Caraveo Caraveo, Inafectabilidad, pp. 65-66 y 97. El decreto de 1은 de marzo de 1937 sobre la inafectabilidad ganadera, así como su reglamento, de octubre del mismo año, se hallan en FabILA, Cinco siglos, pp. 633-635 y 647661, respectivamente.
} 
de la nueva ley de colonización establecían el procedimiento para el pago que los colonos debían hacer por la tierra adquirida, en el que intervendría la CNC; esas sumas formarían parte del Fondo Nacional de Colonización que nacía con la propia ley, y el artículo 24 autorizaba la colonización con "elementos nacionales y extranjeros". Debe quedar claro que los colonos debían pagar sus tierras, los ejidatarios no.

Al menos dos diarios de la capital del país, El Universal y el oficialista El Nacional, saludaron con entusiasmo la propuesta colonizadora del nuevo gobierno. ${ }^{19}$ Lucio Mendieta y Núñez, uno de los primeros sociólogos profesionales de México y experto en materia agraria, se sumó al entusiasmo. Su argumento era sugerente: la Constitución de 1917 había previsto cuatro vías de cambio agrario. Dos de ellas, la restitución y la dotación, habían sido las preferidas, y las otras dos habían quedado prácticamente en el olvido, a saber, la creación de nuevos centros de población y la destrucción de latifundios. Por eso la iniciativa gubernamental era una magnífica idea, ya que además, según sus cuentas, había ya 456000 ejidatarios "con derechos a salvo", es decir, con derecho a dotación pero sin tierra disponible para otorgárselas. Era resultado de que las restituciones y dotaciones habían seguido "la línea del menor esfuerzo" al afectar las propiedades existentes en un radio de siete $\mathrm{km}$, medido a partir de la localización del núcleo solicitante. Esto último, vale la pena subrayarlo, era indicio claro de que el movimiento social agrarista y la política gubernamental habían preferido los terrenos ocupados, densamente poblados, es decir, la antítesis de los supuestos en que descansaba la colonización. El saldo de ésta, a ojos de Mendieta, era pobre: apenas 178 colonias. Entendía este autor que la colonización era un gran negocio, como el

${ }_{19}$ Véanse por ejemplo, del primer diario las notas de 5 y 8 de diciembre de 1946, y 15 y de 18 de enero de 1947; y del segundo diario, las notas aparecidas los días 7,11, 12, 17, 18, 26 y 27 de diciembre de 1946. 
inmobiliario urbano, y como lo mostraban las experiencias en Argentina y Brasil. Pero era consciente de que la colonización encerraba un gran riesgo: "El gran problema está en mantener la voracidad de los capitalistas dentro de límites razonables; por ello, la colonización no puede, no debe quedar en manos exclusivamente de empresas privadas sino bajo el control del Gobierno; ni tampoco ha de ser tarea exclusiva de éste, porque entonces todas las lacras burocráticas la echan a perder" ${ }^{20} \mathrm{Ya}$ se verá que el temor del sociólogo no andaba del todo errado.

A pesar de la muy escasa información, puede afirmarse que el alcance de la colonización en el siglo xx fue modesto, ni de lejos es equiparable al reparto ejidal. Al igual que en la historiografía, en las estadísticas agrarias se aprecia el desdén por la colonización durante el siglo xx. No se sabe por ejemplo en qué periodos ganó intensidad y en qué años la perdió. Lo único que se sabe es que el gobierno alemanista la impulsó con fuerza. Ello se muestra en la estadística que presenta Mendieta y Núñez, que se reproduce en el cuadro $1 .{ }^{21}$

Es evidente que hasta antes de 1946 la colonización había preferido al norte y que la colonización se intensificó después de 1952, especialmente en el sur del país. Sin embargo, también resulta claro que el esfuerzo alemanista por el sur no fue suficiente para extinguir la vocación norteña de este programa gubernamental..$^{22}$

${ }^{20}$ Lucio Mendieta y Núñez, "Urgencia y perspectivas de la colonización", El Universal (miércoles 15 ene. 1947). Una felicitación por la creación de la CNC se halla en AGN, $M A$, c. 569, exp. 545.22/1, telegrama de 16 de diciembre de 1946 de Federico M. Nachón, presidente de la Asociación Pro-Granjas Mexicanas.

${ }^{21}$ Cabe subrayar la vaguedad de la expresión “antes de 1946”. No se sabe a ciencia cierta si se refiere al periodo iniciado en 1926, fecha de expedición de la primera ley de colonización de la época posrevolucionaria.

${ }_{22}$ Antes se dijo que se desconoce el lindero entre el norte y el sur del país empleado por la CNC. Para elaborar el cuadro 1, y en atención a la queja mencionada en la nota 12 , se decidió considerar como punto de referencia al Distrito 
Cuadro 1

TRAYECTORIA DE LA COLONIZACIÓN EN MÉXICO, ANTES Y DESPUÉS DE 1946

\begin{tabular}{lcccccccc}
\hline & \multicolumn{3}{c}{ "Antes de 1946" } & & \multicolumn{3}{c}{ De 1o de dic. 1946 a 31 dic. 1952 } \\
\cline { 2 - 3 } \cline { 7 - 9 } & Colonias & Superficie & Colonos & & Colonias & Superficie & Colonos \\
\hline México & 188 & 1966316 & 14144 & & 191 & 1394066 & 13432 \\
Norte & 161 & 1874189 & 12224 & & 142 & 1128731 & 9521 \\
Sur & 27 & 92127 & 1920 & & 49 & 220335 & 3911 \\
& & & & & & & \\
\% Norte & 85.6 & 95.3 & 86.4 & & 74.4 & 81.1 & 70.9 \\
\% Sur & 14.4 & 4.7 & 13.6 & & 25.7 & 15.8 & 29.1 \\
\hline
\end{tabular}

Fuente: elaborado a partir de Mendieta y NúñEZ, El problema, p. 469.

Por lo visto, la colonización ganó bríos después de 1952, pues una estadística de 1962 indica la formación de un total de 1240 colonias (1105 agrícolas y 135 ganaderas), con 61146 colonos. Estas cifras representan 861 colonias y 33576 colonos más respecto al total alcanzado a fines de 1952. En cuanto a la superficie involucrada, en 1962 las colonias ocupaban "poco más" de siete millones de hectáreas, lo que significa que entre 1952 y 1962 esas criaturas agrarias se extendieron en cerca de 3.6 millones de hectáreas, poco más del doble de la cifra alcanzada hasta 1952. En 1962 las colonias se localizaban sobre todo en los estados de Chiapas y Veracruz en el sur, y Baja California, Chihuahua y Sonora en el norte. ${ }^{23}$ Independientemente de

Federal. De ese modo, el "sur” quedó conformado por las siguientes entidades federativas: Campeche, Chiapas, Guerrero, Morelos, Oaxaca, Puebla, Quintana Roo, Tabasco, Tlaxcala, Veracruz y Yucatán. Los estados de Aguascalientes, Colima y Nayarit no aparecen en la fuente empleada.

${ }^{23}$ Las cifras de 1962 se tomaron de Reyes Osorio, Stavenhagen, Eckstein y Ballesteros, Estructura, pp. 700-701. Sobre la colonización en el sur del país pueden consultarse Ballesteros Porta y Edel, Colonización; el libro de Reyes Osorio, Stavenhagen, Eckstein y Ballesteros, Estructura, pp. 693-747 y el de FORT, La colonización ejidal; y sobre el norte, en relación con Mexicali y el Bajo Bravo, véase León, Crónica, pp. 429-436; sobre la Costa de 
que en el futuro pueda detallarse la labor de la CNC, el peso de las colonias contrastaba con el de los ejidos. A fines de 1964 se habían entregado 57 millones de hectáreas a dos millones de ejidatarios. ${ }^{24}$

Pero más importante que este contraste estadístico es la conclusión que se lee sobre la colonización en un libro clásico sobre el campo mexicano del siglo xx, el de Reyes Osorio y demás autores. Después de afirmar que la superficie de labor en las zonas tropicales del Golfo de México se había incrementado en poco más 1.7 millones de hectáreas entre 1940 y 1960, el estudio concluye explicando el motor de esa expansión agrícola:

El poblamiento de las nuevas tierras se ha realizado fundamentalmente en forma espontánea, a medida que se multiplican las vías de comunicación y las posibilidades de comercio [...] En realidad ha habido pocos ejemplos de colonización dirigida, o sea el traslado por cuenta del gobierno federal de campesinos de zonas con alta densidad demográfica a zonas susceptibles de colonizar. ${ }^{25}$

A la luz del argumento de este trabajo, la conclusión transcrita puede retomarse como una hipótesis de trabajo referida al mayor peso del poblamiento espontáneo y del mercado de

Hermosillo, véase VON DER BORCH, “La colonización”, y MORENo VÁzquEz, Por abajo del agua, pp. 179-186.

${ }^{24}$ EHM 2014, cuadro 9.49.

25 Reyes Osorio, Stavenhagen, Eckstein y Ballesteros, Estructura, p. 701. Pensar en el fracaso o en el muy limitado alcance de la colonización no era algo exclusivo de México. En un libro sobre América Latina se lee: "Los programas de este tipo no han tardado en producir desilusiones entre los pequeños terratenientes que habían colonizado con la esperanza de convertirse en agricultores prósperos e independientes. En muchos casos -que van desde Indonesia hasta las regiones del Amazonas en Brasil- tal desencanto ha dado lugar, rápidamente, a la migración y al estancamiento económico”. Peek y STANDING, “Las políticas”, p. 33. 
tierras, y a la muy escasa influencia de la labor de la CNC y, más allá, a la debilidad del esfuerzo colonizador del Estado mexicano a lo largo del siglo xx. Pero aparte de eso hay algo que no debe soslayarse: si al menos desde 1974, fecha de publicación del extenso libro de Reyes Osorio y colaboradores, se sabía de la importancia del poblamiento espontáneo, ¿por qué éste no atrajo la atención de los especialistas? ¿Por qué en dicho libro se prefirió describir no el motor principal sino algunas experiencias gubernamentales fallidas en materia de colonización? ¿Acaso porque a final de cuentas lo que importaba en ese libro, en ese tiempo, no era tanto el desarrollo agrícola ni el poblamiento sino el desempeño del Estado en esos ramos? Si lo anterior es cierto, estudios como el de Reyes Osorio ilustran bien lo que no interesa hacer en este trabajo, en esta investigación.

\section{ANTECEDENTES CERCANOS Y REMOTOS}

DE LA COLONIZACIÓN

Como se dijo, la CNC nació estrechamente vinculada al callismo, según se reconocía en el dictamen de los diputados mencionado antes y como lo expresa bien la designación del ingeniero León. En particular, destacaba la cercanía con la ley de irrigación con aguas federales de enero de 1926 y con la ley de colonización de abril siguiente. Esta última había reemplazado a la ley de 1883, muy conocida en la historiografía por su papel en la labor de las compañías deslindadoras. Pero la historia iba más allá, como se anotará en seguida.

El interés por la colonización puede rastrearse desde fines del siglo XVI, cuando la corona española intentó poblar con tlaxcaltecas algunos lugares del septentrión novohispano, o bien en relación con los intentos del siglo XviII encaminados a establecer presidios militares junto a los asentamientos civiles. Para algunos, como Teodoro de Croix, tal forma de impulsar el poblamiento era la mejor manera de conservar el dilatado 
septentrión. ${ }^{26}$ Recuérdese que en el siglo XviII la existencia de vastos terrenos escasamente poblados empezó a ser vista como amenaza para la integridad del virreinato. Se temía el avance de rusos, franceses e ingleses desde el norte.

Pero puede decirse que la edad de oro de la colonización fue el siglo XIX, cuando formó parte del proyecto liberal encaminado a impulsar un mercado de tierras que desembocara en la multiplicación de la pequeña propiedad rural, considerada a su vez como la base de la prosperidad general. Era la misma meta que buscaba la ley de desamortización de 1856. A diferencia del siglo xx, la formación de la anhelada pequeña propiedad no entrañaba el ataque a la gran propiedad. ${ }^{27}$

En el siglo xix la colonización adquirió un nuevo componente: los extranjeros. Este se explica no solo por la independencia respecto a España sino también por la emigración resultante de la revolución industrial, originada principalmente en Europa occidental. Los gobernantes mexicanos expresaron una y otra vez el diagnóstico de que México requería una población más abundante. Por ello se dieron a la tarea de buscar colonos extranjeros, a los que se les adjudicaban grandes virtudes laborales y culturales; sin recato, se les consideraba superiores a la débil y escasa población mexicana (unos ocho millones hacia 1860), la mayoría de origen indígena. Se confiaba en que los industriosos, hermosos y católicos europeos harían milagros. Con ellos, y con los grandes atributos que el ser supremo había dado al territorio del joven país (como su localización entre dos océanos), México tenía todo para convertirse en una potencia entre las naciones civilizadas. No en balde había sido el virreinato español más rico. ${ }^{28}$

\footnotetext{
26 Sobre tlaxcaltecas en Coahuila y Nuevo León, véase ADAMs, Las colonias; y sobre los esfuerzos del último tercio del siglo xviII, entre los que destaca la creación de la Comandancia General de las Provincias Internas en 1776, véase Navarro García, Don José de Gálvez, pp. 353-359.

27 Hale, El liberalismo, p. 309.

28 BERNINGER, La inmigración, pp. 21-52.
} 
Este desbordado optimismo criollo pronto tuvo que matizarse. La razón fue la amarga experiencia de Texas, uno de los primeros lugares donde se llevaron a cabo estos planes tan cargados de ilusiones. Los últimos años de vida del general Manuel Mier y Terán expresan bien la impotencia mexicana para retener esa provincia, que rápidamente se llenaba de estadunidenses. Mier y Terán se suicidó en 1832, quizá por lo que veía venir en Texas. ${ }^{29}$ Al igual que militares españoles como De Croix en el siglo XvIII, el general Mier y Terán estaba convencido de que los soldados solos no garantizaban la pertenencia de Texas a México. Podían llegar más soldados, pero si no llegaban más pobladores no había esperanzas. Y no llegaron. Desde entonces, desde 1836 y al menos hasta 1963, cuando desapareció la CNC, la sombra de Texas empañó o al menos acompañó las ideas en torno a la colonización. ¿Cómo promover la colonización extranjera del territorio nacional sin ponerlo en riesgo? Todavía en 1875 el gobierno mexicano otorgó grandes concesiones (seis millones de hectáreas) al especulador de origen alemán Luis Huller en la península de Baja California. Parecía que la experiencia texana no se asimilaba del todo. Grandes privilegios a cambio de la ansiada formación de colonias con nutridos vecindarios. Como sería común en esta clase de proyectos, permanecieron los privilegios (los derechos de propiedad) pero los pobladores brillaron por su ausencia. Para nuestra fortuna, los estadunidenses, a diferencia de Texas, no se interesaron por poblar la península. En 1895 el número de sus habitantes apenas rebasaba los 43000.30

González Navarro ha resumido la experiencia en el ramo aludiendo al pesimismo del secretario de Fomento, Olegario Molina en 1909, postura contrastante con el optimismo colonizador de sus antecesores en el cargo, como Vicente Riva Palacio y Carlos

29 Sobre Mier y Terán, personaje que bien merece una nueva biografía, véase Morton, Terán and Texas.

30 Sobre Huller, véase RiguzzI, “La encrucijada”, pp. 182-187; y EHM 2014, cuadro 1.20. 
Pacheco. Molina no tenía empacho en reconocer que la empresa colonizadora, pública y privada, había fracasado, porque "ninguna de las dos adelantó en la resolución de los graves problemas demográfico y agrícola del país". ${ }^{31}$ Algunos pocos italianos, mormones estadunidenses, alemanes, rusos, griegos y japoneses se asentaron en diversos puntos del país. Pero nada que ver con las enormes cantidades de migrantes que por esos mismos años llegaban a Argentina, Brasil y sobre todo a Estados Unidos.

A la vuelta de siglo, el desaire de los colonos extranjeros hizo flaco favor a la colonización y a las ideas liberales que la sustentaban. Ante el estallido de la revolución de 1910 y con la aparición del zapatismo, aquellas viejas ideas se debilitaron aún más. En ese momento ganó preponderancia una corriente política que proponía restituir los terrenos a los pueblos despojados, buscando asegurar la autosuficiencia económica de los vecindarios. ${ }^{32}$ Con esa restauración de la propiedad comunal, colectiva, la antigua unidad poblamiento-propiedad privada, la base de la colonización decimonónica, sufrió un embate inusitado. La demanda agraria mostraba que la población rural sí existía y que también existía la injusticia del acaparamiento de tierras, los latifundios. Una ecuación por completo distinta a la que subyacía a la colonización, es decir, terrenos vacíos y escasa población. Más que demandar terrenos inexplotados o de baja densidad de población, los zapatistas y luego los agraristas en general demandaron las tierras de las grandes propiedades, es decir, de las unidades productivas en funcionamiento, que muchas veces se habían transformado en asentamientos de cierta jerarquía. ${ }^{33} \mathrm{Tal}$ era el sentido del decreto de 6 de enero de 1915, retomado luego por el artículo 27 constitucional y por el conjunto de leyes que normaron lo que con el tiempo se convirtió en una gigantesca

31 En González Navarro, La colonización, p. 8.

32 Kourí, "Los pueblos".

33 García Martínez, "Los poblados”. 
reforma agraria, organizada de manera creciente por la vía de la dotación de ejidos.

Sin embargo, el ascenso de las ideas en torno a la urgencia de restituir las tierras a los pueblos despojados y de dotar a los núcleos carentes de ellas, no significó en modo alguno la desaparición de la postura que insistía en el fraccionamiento de las grandes propiedades para dar lugar a las pequeñas propiedades privadas. Tal postura, calificada de "liberalismo social” por Jesús Silva Herzog, fue expresada por distintos grupos y organismos una vez que el "problema agrario" se consolidó como prioridad indiscutida de los bandos revolucionarios. ${ }^{34}$ Y ello ocurrió sobre todo después de la publicación del Plan de Ayala, de noviembre de 1911, que marcó la ruptura del zapatismo con el gobierno del presidente Francisco I. Madero. La persistencia de esas ideas puede leerse en varios folletos compilados por el mismo Silva Herzog. Cabe mencionar las propuestas de la Secretaría de Fomento maderista, en voz del ingeniero Leopoldo Viadas, y las de Wistano Luis Orozco. ${ }^{35}$ También hay que considerar la ley agraria del villismo, de mayo de 1915, que proponía fraccionar las grandes propiedades mediante expropiaciones a cargo de los gobiernos locales y enajenar los lotes resultantes "a los precios de costo”, sin considerar ni la restitución ni la dotación. ${ }^{36}$ En ese sentido, la ley era diametralmente distinta al Plan de Ayala y al entonces reciente decreto de 6 de enero de 1915, emitido por el primer jefe constitucionalista Venustiano Carranza.

La existencia de diversas vías para acabar con los latifundios y hacer justicia al pueblo carente de tierras se aprecia también en el artículo 27 de la nueva Constitución general de 1917. Al final de dicho artículo se lee que los estados, de conformidad con las leyes que emitieran sobre el ramo, quedaban obligados

\footnotetext{
34 Tal calificativo en Silva Herzog, El agrarismo, p. 188.

35 Silva Herzog, La cuestión, I. Véase al respecto el folleto de L. Viadas (pp. 109-165) y el de W. L. Orozco (pp. 245-264).

36 La ley villista se halla en Córdova, La ideología, pp. 465-470.
} 
a determinar no solo el tamaño de la pequeña propiedad sino también el procedimiento a seguir para fraccionar las superficies excedentes. Y ese procedimiento no culminaba necesariamente en restituciones o dotaciones de ejidos. En el inciso b) del penúltimo párrafo del famoso artículo se lee que "El excedente de la extensión fijada deberá ser fraccionado por el propietario en el plazo que señalen las leyes locales; $y$ las fracciones serán puestas a la venta en las condiciones que aprueben los gobiernos de acuerdo con las mismas leyes". ${ }^{37}$

En los primeros años posrevolucionarios algunos estados se tomaron muy en serio el mandato constitucional. Uno de ellos fue el de Chihuahua, como puede apreciarse en la ley agraria local de mayo de 1922.

Vale la pena ahondar en el caso chihuahuense, al menos en dos episodios de 1922-1923. El arribo de los menonitas al estado en 1922 no solo exhibió la persistencia de la postura favorable a la colonización extranjera aun después de la revolución de 1910. Además, al admitir a los menonitas el presidente Álvaro Obregón desestimaba el conflicto agrario propiamente dicho. Tal era el reclamo que el gobernador Ignacio Enríquez, un liberal de cepa, hacía a Obregón. El general Enríquez no ocultó su disgusto por el arribo menonita alegando la mala situación de miles de mexicanos sin tierras. Pero lo notable es que ni en la cuestión menonita ni en la crítica de Enríquez a Obregón se hallaba el reparto ejidal. Cabe explicar. Dos empresas menonitas habían adquirido 60000 hectáreas del latifundio de la familia Zuloaga (300000 hectáreas) a un costo de poco más de un millón de dólares. Así, los Zuloaga ganaban por partida doble: además del negocio inmobiliario, se salvaban de las afectaciones ejidales, al menos en esa porción del latifundio. ${ }^{38}$

${ }_{37}$ Diario Oficial de la Federación (lunes 5 feb. 1917) (cursivas mías).

${ }^{38}$ Se hace esta aclaración porque al tiempo que negociaban con los menonitas, los Zuloaga enfrentaban un poderoso movimiento agrarista que los obligó a aceptar la dotación del ejido de San Antonio de los Arenales, una pequeña 
Tal era la posibilidad que abría la colonización a los terratenientes: evitar las afectaciones ejidales y hacer negocio con la división de la gran propiedad. Y eso era precisamente lo que la ley local de 1922, siguiendo el artículo 27 constitucional, pretendía hacer. Además, el gobierno de Enríquez buscaba fraccionar los latifundios mediante tratos de compraventa entre particulares, sin la intervención gubernamental. El desenlace previsto por la ley local era la formación de colonias de pequeños propietarios. ${ }^{39}$

La situación es compleja porque el mismo Obregón, quien había autorizado el arribo menonita, se opuso a la ley agraria de Enríquez, su fiel compañero de armas contra Villa. Y por ello, frente al gobernador chihuahuense y desde Chihuahua, el presidente Obregón aparecía exactamente como lo que no era: furibundo agrarista-ejidalista, si puede decirse así. Su alianza con el Partido Nacional Agrarista tenía su razón de ser.

La oposición presidencial a la colonización al modo del liberal gobierno chihuahuense, siguiendo el propio artículo 27 constitucional, según acaba de decirse, influyó más tarde en la ruptura de Enríquez con Obregón (y Calles). Pero tal ruptura no se explica del todo sin considerar el llamado "asunto McQuatters", relativo al fraccionamiento del latifundio de Luis Terrazas, de 2.6 millones de hectáreas. En este caso, el gobernador Enríquez imaginó un audaz proyecto: un grupo de capitalistas estadounidenses, encabezados por Arthur J. McQuatters, adquiriría el latifundio y luego lo fraccionaría y vendería a agricultores

localidad formada alrededor de la estación del Ferrocarril del Noroeste. Esa dotación ejidal influyó en el nacimiento de Ciudad Cuauhtémoc en 1927, la tercera del estado de Chihuahua en la actualidad. De haber ocurrido después de 1947, el trato con los menonitas habría quedado cobijado por la legalidad alemanista. Quizá la mencionada veda ejidal de cinco años habría evitado la dotación y habría impedido o al menos dificultado el surgimiento de dicha ciudad.

39 Esas colonias han sido estudiadas por Domínguez Rascón, La política. 
mexicanos (medieros, aparceros, arrendatarios). Se formarían así colonias de pequeños propietarios en lugar de ejidos. Pero Obregón canceló el trato con McQuatters, a pesar de haberlo aprobado en un principio. En parte lo hizo por la fuerte protesta de Pancho Villa, acérrimo enemigo no solo del presidente y del gobernador sino también de Luis Terrazas, quien aún vivía. ${ }^{40}$ El presidente Obregón decidió adquirir el latifundio, pagando poco más de 13 millones de pesos por él. Quizá como modo de imponer el ejido en un escenario rural de liberalismo subido, entre 1926 y 1928 el gobierno callista repartió más de 600000 hectáreas ejidales en Chihuahua. ${ }^{41}$ En ese tiempo en ningún otro lugar del país los ejidos alcanzaban semejante extensión. Esa superficie incluía la de los antiguos ejidos otorgados a los vecinos de las colonias formadas durante la época de los borbones. Una de ellas era Namiquipa, tema del libro del recordado Daniel Nugent. En ese lugar, como en otros, los vecinos repudiaban el ejido. Querían seguir siendo propietarios privados, agricultores independientes, pagar impuestos y vivir libres de tutelas gubernamentales. ${ }^{42}$ Casi sobra decir que ni la vía liberal de cambio agrario en el siglo xx ni esta oposición popular, pueblerina, al reparto ejidal, han sido estudiadas a fondo.

El asunto es más complejo porque no solo un exótico gobernador de una presunta periferia norteña propugnaba por la formación de colonias en lugar de ejidos, es decir, una colonización entendida ya con el sello del siglo xx posrevolucionario: sin extranjeros y como vía no solo distinta sino antagónica del reparto ejidal. Lejos de eso, la colonización estaba plenamente vigente entre las nuevas autoridades a cargo del gobierno federal, en la misma capital del país, como se expondrá en seguida.

40 Sobre el arribo menonita, los Zuloaga, la ley chihuahuense de 1922, el asunto McQuatters y la lucha por el ejido de San Antonio de los Arenales, véase Aвoites Aguilar, Norte precario, pp. 155-211.

41 Aboites Aguilar, Cuentas, cuadro B1-3.

42 Nugent, Spent Cartidges. 
El gobierno del presidente Plutarco Elías Calles diseñó un programa para fraccionar latifundios y crear la tan anhelada clase media rural, formada por pequeños propietarios privados. Pero lo hizo con una innovación típica del siglo xx, muy poco liberal por lo demás: la inversión pública, en este caso mediante la construcción de obras de riego y la colonización de los terrenos irrigados. Tal era la misión de la Comisión Nacional de Irrigación (CNI en adelante), nacida en 1926. Por ese afán colonizador, la CNI puede considerarse ancestro directo de la CNC. ${ }^{43}$ El ingeniero León, en su carácter de secretario de Agricultura y Fomento, era el responsable de la iniciativa callista. Por ello la importancia que reviste su nombramiento de 1947 al frente de la sección norte de la CNC.

El artículo 5 de la ley de irrigación de 1926 resume este agrarismo irrigador, por llamarle de algún modo. En ese artículo se fijaba el procedimiento para fraccionar los latifundios: la CNI construiría obras de riego que beneficiarían a distintas porciones de las grandes propiedades y, por el interés público consagrado en el artículo 27 constitucional, la ley obligaba al terrateniente a aceptar el intercambio entre cientos o miles de hectáreas de terrenos eriazos y por tanto de escaso valor, por una parcela de riego con valor equivalente al de la superficie perdida. Los terrenos que perdía el latifundio, y que por obra y gracia del dinero público se convertían en terrenos irrigados, serían vendidos a pequeños agricultores. Es importante subrayar que la venta no la realizaba el terrateniente (como pretendía Enríquez) sino el gobierno federal a través de la CNi y más tarde por medio del Banco Nacional de Crédito Agrícola. Asunto crucial. Así se

${ }^{43} \mathrm{La}$ CNI fue creada por la ley de irrigación con aguas federales, publicada en $D O F$ (sábado 9 ene. 1926); la ley de colonización que le siguió en DOF (martes 11 mayo 1926). Es notable la semejanza que guarda el diseño institucional de la CNI con la propuesta sobre irrigación hecha por los tres miembros de la comisión agraria ejecutiva en mayo de 1912. Al respecto, véase Silva Herzog, La cuestión, II, pp. 212-213. 
lograría el propósito callista de destruir el latifundio de manera creativa, pero también de situar al Estado como mediador entre los viejos grandes propietarios y los nuevos pequeños propietarios. Por lo visto, la consigna era que nada de lo agrario quedara fuera o al margen del Estado (ni la historiografía, cabe agregar). Lo que no aparecía de nuevo era el ejido. Para estos callistas, el ejido era asunto de justicia revolucionaria, no de fomento económico. Lo realmente importante, como la innovación tecnológica, el aumento de cosechas y en general la estabilidad y el progreso del país, era tarea de los nuevos propietarios privados, de los "colonos", como los denominaba la CNI. Repetían los callistas las viejas ideas liberales acerca de que el aumento de propietarios traería prosperidad, felicidad y paz a la patria. ${ }^{44}$

Pero la colonización al modo callista no lo era solamente por el corolario privatizador. También lo era porque recogía la preocupación por el poblamiento. Desde el inicio la CNI mostró su predilección por emprender las obras de mayor envergadura en el norte del país. Y la razón no era otra que la necesidad, aún considerada urgente, de reforzar la ocupación de esa porción del territorio nacional, limítrofe con el poderoso y ambicioso país vecino. ${ }^{45}$ Así, a la destrucción creativa de los latifundios se sumaba la idea de "colonizar" los sistemas nacionales de riego

\footnotetext{
${ }^{44}$ Sobre la aplicación de estas ideas en el sistema nacional de riego del río Conchos, Chihuahua, véase Aвortes Aguilar, La irrigación, pp. 172-201. En este caso, siete grandes propiedades se fraccionaron y dieron lugar a poco más de un millar de predios privados. Si en algún lugar del país el agrarismo liberal callista tuvo éxito fue precisamente en el actual distrito de riego 05, al menos en los primeros años. Luego llegaron veteranos de la Revolución y demandantes de ejidos y la historia fue muy otra.

${ }_{45}$ Acerca de la preocupación por el poblamiento de la frontera norte, véase "La política de irrigación del gobierno federal", "La política agrícola de la Comisión" y "Nuestro concepto de colonización”, todos editoriales de la revista Irrigación en México, órgano oficial de la CNC, de los siguientes números: ı: 2 (jun. 1930), pp. 9 y 11; II: 4 (feb. 1931), pp. 293-295; y II: 5 (mar. 1931), pp. 389-391, respectivamente.
} 
y crear en ellos ciudades agrícolas, concebidas como cabeceras de esos sistemas de riego construidos por la inversión gubernamental. Esa política de irrigación-colonización también buscaba reforzar la soberanía nacional en materia de aguas, aumentando los aprovechamientos de los afluentes del río Bravo. ${ }^{46}$

La irrigación al modo callista enfrentó múltiples críticas. Quizá la más importante era su limitado alcance y el elevado costo de las obras. A fines de 1934, ocho años después de fundada la CNI, el presidente Abelardo Rodríguez informaba que en los diez sistemas de riego existentes en el país se habían abierto 113000 hectáreas donde se habían instalado 11200 colonos. Esa superficie no significaba ni $1 \%$ de la superficie ejidal entregada hasta entonces; por su parte, el número de colonos representaba poco más de ese porcentaje del total de 878000 ejidatarios. ${ }^{47}$

Contra lo que pudiera esperarse, los magros resultados de la CNI no la debilitaron. En la continuidad y aun en el fortalecimiento de la irrigación influyó de manera decisiva el presidente Cárdenas, adalid del ejido pero también de la irrigación en el norte del país, quizá por su notable devoción algodonera (rasgos suyos que tampoco han sido estudiados). En 1937 dieron inicio tres magnos proyectos: El Palmito, sobre el río Nazas; la Angostura, sobre un afluente del río Yaqui, y El Azúcar, sobre el río San Juan, en Tamaulipas. En 1939 agregó otro más: el de la presa Sanalona, que permitió la expansión del valle de Culiacán. Cuatro grandes proyectos norteños. En eso no había ruptura con Calles. Pero sí la había con respecto a la combinación irrigación-colonización. Cárdenas era entusiasta irrigador pero no colonizador. El michoacano prefería que pequeñas propiedades y ejidos compartieran los beneficios de las obras de riego. Por ello insistía en algo fundamental en el argumento de este trabajo: que por igual la pequeña propiedad privada y la ejidal

\footnotetext{
$46 \mathrm{Al}$ respecto, véase SAmANiego, Ríos internacionales.

47 Los presidentes, III, p. 1277; y EHM 2014, cuadro 9.49.
} 
eran producto de la revolución de 1910 y que por ello urgía dar garantías a una y otra. ${ }^{48}$ De eso hablan por un lado los grandes repartos ejidales en La Laguna, Valle del Yaqui y de Mexicali, algo que ni por asomo habían hecho los obregonistas y los callistas. Pero por otro lado también hablaba el hecho de que la acción agraria ejidal no había significado de ninguna manera la desaparición de los predios privados; al contrario, el mismo reparto ejidal había estimulado un mercado de tierras que se había traducido en la multiplicación de ese tipo de predios en los años que siguieron al reparto ejidal. Casi sobra decir que el mercado de tierras, a diferencia de los ejidos colectivos, ha recibido muy poca atención de los estudiosos. El movimiento mercantil, espontáneo, apuntaló el cambio agrario en una magnitud que no se conoce con precisión. ${ }^{49}$ Sobre el Bajo Bravo, León afirmaba en 1950 que "en la región hay 'fiebre' por abrir tierras, y todos están dominados por la obsesión de sembrar [...] principalmente algodón”. ${ }^{50}$ No es casualidad además que en la década de 1940 empezara a formarse otro mercado, el de trabajo, compuesto por jornaleros agrícolas originarios del centro y sur del país. ${ }^{51}$ Así se completaba la ecuación: ejidos y predios privados en ascenso, auge de la agricultura, mano de obra barata y grandes inversiones públicas. El milagro agrícola en ciernes.

En ese contexto nació la CNC. Cabe preguntarse por qué en 1946 el presidente Alemán consideró oportuno crear una institución dedicada exclusivamente a la colonización. La respuesta, que de hecho es una de las hipótesis de este texto, es que la CNC

48 Véase entre otros su discurso de 3 de mayo de 1938, en EsCÁrCEGa López y Caraveo Caraveo, Inafectabilidad, p. 95; y la circular del Departamento Agrario de 31 de marzo de 1938 urgiendo a proteger la pequeña propiedad, en FaBILA, Cinco siglos, pp. 666-668.

49 Sobre el rápido crecimiento del número de predios privados en La Laguna y el valle de Mexicali entre 1936 y 1950, justo después de los grandes repartos cardenistas, véase Авоiтes Aguilar, El norte entre algodones, pp. 198-199.

50 León, Crónica, p. 433.

51 Astorga Lira, Mercado. 
nació con tres propósitos principales: a) reanimar la inversión privada en el campo, $b$ ) fortalecer la propiedad privada rural y sacarla del rincón ideológico y político al que la había arrumbado el reparto ejidal cardenista, y c) quizá el más importante, reforzar la intervención del Estado en un movimiento mercantil que ganaba cada vez más fuerza conforme mejoraban las condiciones del negocio agrícola. Como se dijo, los predios privados se multiplicaron después de 1937 en las zonas arriba mencionadas y en otras sin necesidad de Estado en sentido estricto. Pero más adelante, gracias a las gigantescas inversiones gubernamentales en riego, el crecimiento de la propiedad privada rural alcanzó su momento culminante. ${ }^{52}$ No por otra razón el vocal ejecutivo de la zona norte de la CNC, Luis León, quedó a cargo de la colonización de las crecientes superficies de los distritos de riego, construidos por la Secretaría de Recursos Hidráulicos y manejados por esa misma secretaría desde 1951.

\section{RAZONES PARA LA EXTINCIÓN ¿1959 Y/O 1963?}

Puede decirse que la CNC tuvo dos fechas de fallecimiento, separadas por cuatro años. La primera, 1959, es administrativa, y la segunda, 1963, es de carácter legal. La primera tiene que ver con la creación del Departamento de Asuntos Agrarios y Colonización (DAAC en adelante). En enero de 1959 un decreto presidencial trasladó varias facultades y atribuciones de la SAG al DAAC; se refería a la promoción agrícola ejidal, al manejo de los terrenos nacionales y baldíos y por supuesto a la colonización. En lugar de la CNC, el DAAC contaría con una dirección de colonización, el rango que había tenido el ramo antes de 1947, según se dijo. Así que no solo se trataba de un cambio de adscripción

52 Por lo visto, la prioridad por el riego castigó otros ramos, como el crédito agrícola, especialmente aquel destinado a ejidos; en tiempos alemanistas casi se extinguió. Véase Medin, El sexenio alemanista, p. 134. 
sino de un drástico descenso burocrático dentro de la administración pública federal. Los autores de un libro especializado tienen razón cuando afirman que la CNC "desapareció a fines de 1958". ${ }^{53}$ Pero no la tienen si se considera, entre otras cosas, que la legislación de 1946 (la ley de creación de la CNC y la ley de colonización) permaneció intacta.

Dato importante es que la persona designada para encabezar el naciente DAAC, Roberto Barrios, tenía poco que ver con los catrines norteños que habían dirigido la CNC, como Ortiz Garza y León. Barrios era un maestro normalista originario del Estado de México (Atlacomulco, 1908), y por ello paisano del entonces presidente de la República. En su hoja de méritos aparecía algo que quizá ofendía a los promotores de la CNC alemanista: había sido el tercer secretario general de la Confederación Nacional Campesina (1947-1950). ${ }^{54}$

Como se dijo, la segunda muerte de la CNC ocurrió cuatro años después del decreto de enero de 1959. En enero de 1963 entró en vigor una ley que reformaba el código agrario y que derogaba las leyes de colonización y de la CNC. Ahora sí el desenlace era contundente: el gobierno del presidente Adolfo López Mateos echaba abajo no solo la colonización al modo alemanista sino que borraba la colonización para siempre (al menos hasta ahora) de la historia de México.

Cabe dar algunas referencias del contexto de la segunda muerte de la CNC. Quizá la demografía tenía su peso: en 1960 el país contaba con 35 millones de habitantes, cuatro veces más que un siglo antes. Además, la elevada tasa de crecimiento demográfico empezaba a alarmar a algunos y a enterrar uno de los viejos supuestos en que descansaba la colonización: la escasez de habitantes. En 1965 el jefe del DAAC afirmaba que "El problema

53 DOF, martes 13 de enero de 1959; Reyes Osorio, Stavenhagen, Eckstein y Ballesteros, Estructura, p. 700.

${ }^{54}$ Sobre la sumisa gestión de Barrios al frente de la Confederación, véase González Navarro, La Confederación, pp. 128-135. 
agrario actual resulta de una creciente presión demográfica" ${ }^{55}$ Puede proponerse, sin embargo, que la razón principal de la muerte de la CNC fue la amplia inconformidad que había generado la colonización al modo alemanista.

En efecto, las voces críticas acerca de la reciente gestión colonizadora se acumularon a lo largo de los años. En 1960 un grupo de diputados sostenía que "la colonización en los últimos tiempos autorizada con relación a terrenos particulares ha sido un camino propicio para eludir la aplicación del Código Agrario”. En una memoria del mismo año, el propio DAAC señalaba que "por lo que se refiere a la colonización, esta vía ha dejado de ser medio para que simuladores del trabajo agrícola, adquirieran terrenos nacionales, con los que se constituían verdaderos latifundios en perjuicio de la clase rural" ${ }^{56}$ Otros aludían a la amarga historia del siglo xix. Así, en 1960 un diputado adjudicaba a la colonización "parte de la culpa de haber perdido parte [sic] del territorio nacional”. En 1962 el senador Manuel Hinojosa Ortiz afirmaba:

Si hiciéramos una síntesis histórica de los resultados económicos de las ideas y las leyes sobre colonización, pudiéramos decir que tanto en el pasado como en el presente siglo, la colonización solo tuvo dos efectos contraproducentes, perjudiciales para el pueblo de México: por un lado, la especulación; por otro lado, la simulación.

55 Aguirre Palancares, Ceremonia, p. 12. Cinco años antes, en 1960, el propio DAAC se refería a los "complejos y graves problemas resultantes del vigoroso crecimiento demográfico”. Véase DAAC, Memoria 1960-1961, s/p.

56 DDD, miércoles 28 de diciembre de 1960, carta suscrita por 35 diputados para derogar la ley de colonización y extinguir la CNC; DAAC, Memoria 19591960, s/p; en 1959 la CNC cardenista pidió reformar la ley de colonización “porque permitía [que] se formaran nuevos latifundios”. Véase GonzÁLEZ Navarro, La Confederación, p. 144. También véase Silva Herzog, El agrarismo, p. 493, y Reyes Osorio, Stavenhagen, Eckstein y Ballesteros, Estructura, pp. 699-700. 
Otro senador, Natalio Vázquez Pallares, hacía un recuento más detallado. La colonización se había visto involucrada en: a) la pérdida de Texas, b) la "depredadora" labor de las compañías deslindadoras, c) el acaparamiento de las tierras de los distritos de riego que "han sido objeto codicioso de cierto tipo de agricultores" y $d$ ) "el fraccionamiento simulado de latifundios" gracias a las leyes de 1946, para eludir la demanda agraria..$^{57}$ Algunos pocos la apoyaban, o al menos defendían la colonización, alegando que cada colono era un ejidatario menos que mantener. ${ }^{58}$ Pero esta clase de argumentos favorables, tan nutridos y entusiastas en 1946-1947, no bastaron en 1960-1963. El temor expresado por Mendieta y Núñez en 1946 acerca de la voracidad de los empresarios parecía haberse confirmado. ${ }^{59}$ No había engaño. Desde 1912 Luis Cabrera había alertado sobre las maniobras de algunos:

Se pensó inmediatamente en comprar tierras baratas para vendérselas caras al Gobierno, a fin de que éste satisficiese las necesidades de las clases proletarias. Entonces fue cuando por primera vez maldije a esos hombres que no pueden ver un dolor o un sufrimiento

${ }^{57} \mathrm{DDD}$ (miércoles 28 dic. 1960), intervención del diputado Vicente Salgado Páez; Diario de los Debates de la Cámara de Senadores (DDS en adelante), miércoles 26 de diciembre de 1962, pp. 27-28, intervenciones de los senadores Manuel Hinojosa Ortiz y Natalio Vázquez Pallares. Una crítica más amplia y articulada a la colonización al modo alemanista y en general a la trayectoria de esta política de cambio agrario se halla en la conferencia de 1962 de López Serrano, Colonización, pp. 22-24. El autor era alto funcionario del DAac.

58 Tal era la postura del abogado Ibarrola, Derecho agrario, p. 508; y de MendieTA y Núñez, El problema, pp. 468-470.

59 En notable contraste con la cobertura de 1946-1947, los diarios capitalinos El Universal y El Nacional dieron poco espacio a la extinción de la colonización. El primer diario solo publicó una nota, el 27 de diciembre de 1962, y el segundo recogió las posturas anticolonizadoras del gobierno en turno (notas de 15, 27 y 28 de diciembre de 1962). 
sin pensar inmediatamente en cuántos pesos pueden sacarse de cada lágrima de sus semejantes. ${ }^{60}$

Luego de la creación del DAAC a fines de 1958, el presidente López Mateos prosiguió lo que bien puede considerarse su cruzada anti-colonizadora. El 1o de julio de 1960 en Guaymas, donde pronunció el famoso discurso sobre la "extrema izquierda” de la Constitución de 1917 y de su gobierno, el presidente anunció la decisión de dedicar los terrenos nacionales a la dotación de ejidos, lo que significaba sustraer una de las dos partes del objeto de la labor colonizadora; la otra parte, según se recordará, eran los terrenos privados. El Poder Legislativo no tardó en respaldar la decisión presidencial. A fines de ese mismo año de 1960, la Cámara de Diputados aprobó una reforma al código agrario que derogaba las dos leyes colonizadoras de $1947 .{ }^{61}$ Pero el trámite se detuvo. Extrañamente el dictamen de los diputados tardó dos años en llegar a la Cámara de Senadores. Todavía en noviembre de 1962 la Confederación Nacional Campesina expresó su respaldo a la "radical supresión" de la colonización. ${ }^{62}$ Por fin, el 26 de diciembre de 1962, luego de dos años en el limbo, el Senado atendió el dictamen de los diputados; tras breve discusión, la reforma legal fue aprobada por unanimidad. ${ }^{63}$

La "ley que adiciona el artículo 58 del Código Agrario y deroga la ley federal de colonización y la ley que creó la Comisión Nacional de Colonización” entró en vigor en enero de 1963. ${ }^{64} \mathrm{El}$ nuevo artículo establecía algo fundamental: “queda

60 En Silva Herzog, La cuestión, II, pp. 284-285.

$61 D D D$ (miércoles 28 dic. 1960): se presenta la iniciativa de cambio al artículo 58 del código agrario, suscrita por 35 diputados del sector campesino, entre ellos Enrique Olivares Santana, y el mismo día se aprueba por 114 votos a favor y uno en contra.

62 González Navarro, La Confederación, p. 153.

63 DDS (miércoles 26 dic. 1962), p. 30.

${ }^{64} \mathrm{DOF}$ (martes 22 ene. 1963). 
prohibida la colonización de propiedades privadas". Esta era la médula de la reforma, pues anulaba ahora sí por completo el objeto del deseo colonizador del gobierno alemanista. En los artículos transitorios se definía la ruta a seguir con los restos de la institución extinguida y con sus criaturas: aquellas colonias que habían alcanzado a formarse. El primer transitorio derogaba las leyes que daban vida a la CNC. El segundo otorgaba al DAAC las funciones de vigilancia de las colonias existentes que antes ejercía la $\mathrm{CNC}$; el tercero establecía que el fondo de colonización, compuesto por los ingresos derivados de los pagos de los colonos, pasaría a manos del DAAC, y que éste los emplearía para dar vida a una nueva criatura, los "nuevos centros de población ejidal"; el cuarto suspendía la formación de nuevas colonias; el quinto autorizaba al DAAC a declarar la caducidad de concesiones de proyectos en trámite o en incumplimiento, y el sexto era el remate: los terrenos de las colonias desaparecidas volverían al reino victorioso del reparto ejidal pues se declaraban afectables o bien disponibles para la creación de nuevos centros de población ejidal, cuya importancia apenas empieza a palparse. ${ }^{65}$ En suma, el ejido devoraba a la colonización y, más allá, puede decirse, el siglo xx lo hacía con el xIx.

Tal vez los dos años que tardó el traslado del dictamen legislativo de una cámara a otra sean la clave para rastrear la oposición al propósito de acabar con la colonización en México, algo que podrá dilucidarse en el futuro. ${ }^{66}$ Sea lo que sea, un abogado afirma que la reforma al código agrario de principios de

\footnotetext{
${ }^{65}$ Además de los trabajos de la década de 1970 (como el de ForT, La colonización, sobre Quintana Roo), en la actualidad dos jóvenes estudiosos los analizan en profundidad: Torres-Mazuera en la península de Yucatán y en la de Baja California Víctor Gruel, éste en su investigación de tesis doctoral en El Colegio de México.

${ }^{66}$ Sólo el diario capitalino Excelsior (jueves 27 dic. 1962) reparó en esa tardanza. Véase el editorial "Derogó el senado la Ley de colonización. Sólo en último extremo será afectada la propiedad privada".
} 
1963 dio fin "a siglo y medio de colonización estatal o privada tendiente a crear propiedades particulares, para dar paso a la colonización ejidal mediante la creación de nuevos centros de población ejidal". ${ }^{67}$

\section{CONCLUSIONES}

La CNC es pretexto o puerta de acceso para investigar lo que más interesa, a saber, los propietarios privados rurales durante el siglo xx. Estudiarlos es importante, entre otras cosas, porque hicieron realidad el sueño de las élites liberales del siglo xIx: crear una amplia clase de pequeños propietarios rurales. Asimismo, ese grupo de propietarios había contribuido al logro de otro sueño, algo que en el siglo xIx ni por asomo interesaba, a saber, dar fin a los latifundios. Éste era el gran sueño revolucionario de 1910, sueño cumplido sin la menor duda.

En 1966 los propietarios privados sinaloenses contaban algo de su historia:

Nosotros [...] hablamos a nombre de un organismo que representa a todos los pequeños propietarios del Estado [...] de Sinaloa. Somos trabajadores agrícolas que trabajamos conforme a una institución producto de la reforma agraria, ya que, como lo ha dicho el señor Presidente de la República, el ejido y la pequeña propiedad son creaciones de nuestro gran movimiento armado. Entendemos que sin la Reforma Agraria, no hubiere sido posible que surgiéramos como productores agrícolas, en las condiciones que actualmente tenemos.

En las actividades del campo, al igual que en los demás sectores productivos de la nación, ha surgido una importante clase media,

${ }^{67}$ Ruiz Massieu, Temas, p. 90. En su intervención citada, el senador Vázquez Pallares también afirmaba que "el dictamen que se acaba de leer tiende en lo substancial a suprimir de plano el sistema de colonización en México”, y que hacerlo era un "paso progresista en la política agraria de la Revolución". 
que se reconoce es y ha sido factor de primera importancia para el desenvolvimiento de los pueblos. Muchos de nosotros, los pequeños propietarios más afortunados, formamos ya parte de esa clase media. Deseamos prosperar en beneficio propio y de nuestras familias, pero sin desconocer que al hacerlo, tenemos la obligación de procurar que todos quienes participen en la actividad, también alcancen su mejoría. ${ }^{68}$

Conviene terminar diciendo que la breve vida de la CNC es apenas un síntoma. Detrás de ella se hallaban los grupos de propietarios o de aquellos que aspiraban a serlo y que por las buenas o no tan buenas, con apoyo gubernamental o sin él, multiplicaban los predios privados rurales a lo largo y ancho del país. Recuérdese que en esos años la agricultura era un atractivo negocio. ¿De qué servían una ley y una comisión de colonización que parecían redundantes con el movimiento ascendente de los propios propietarios? Además, en cuanto a la política, cada vez resultaba más difícil para el gobierno federal sostener una alianza semejante con la clase propietaria. Y ello porque desde finales de la década de 1950 la inconformidad rural iba en ascenso. Varios asesinatos de agraristas, ocurridos antes del más conocido de Rubén Jaramillo en 1962, son prueba de ello. El problema es que el contexto de esos crímenes no ha llamado la atención como debiera, quizá porque a nuestros ojos la década de 1950 sigue avasallada por los épicos y glamurosos años sesenta.

${ }^{68}$ Análisis, s/p. Se trata de un número especial del boletín mensual de la Confederación de Asociaciones Agrícolas del Estado de Sinaloa (CAADES), que contiene el "Escrito leído por el señor Alfredo Careaga Cebreros, ante el señor ingeniero Norberto Aguirre Palancares, jefe del Departamento de Asuntos Agrarios y Colonización, en el Palacio de Gobierno del Estado de Sinaloa, en Culiacán, el día 6 de julio de 1966”. Se localiza en el AHES, sin clasificación, en un paquete denominado "CAADES 1967-1973". Sobre la CAADES, véase Grammont, Empresarios. 
La propuesta general es que la CNC revela ante todo el intento fallido del Estado por regular la expansión espontánea de la propiedad privada rural, que se hacía no tanto con base en terrenos nacionales sino con los terrenos poseídos por los propios propietarios desde generaciones anteriores (como los Zuloaga), o por propietarios advenedizos bien relacionados como en el Bajo Bravo (los llamados agricultores nylon), o bien en las superficies resultantes del propio quehacer del Estado, ya fuera en las superficies recién abiertas al riego, o bien en terrenos ejidales, la criatura predilecta de la justicia posrevolucionaria. Esto último se refiere al rentismo de parcelas ejidales, cuya importancia creció a lo largo de la década de 1950. ¿Para qué armar colonizaciones si las parcelas ejidales estaban al lado y a la mano, en muchos casos con acceso al riego?

Al extinguirse la colonización en 1963, quedó claro que en adelante el Estado dejaría hacer y pasar en este ramo, contando en todo caso con el agrarismo y con la Confederación Nacional Campesina como factor de contrapeso y equilibrio. Pero cabe preguntarse cómo afectó a la nueva clase de pequeños propietarios el colapso del algodón en 1956, lo mismo que el fin del programa bracero en 1964, así como la aparición de los primeros síntomas de la crisis de la agricultura temporalera. ${ }^{69}$ Cabe preguntarse de igual modo si desde entonces, y sin las grandes inversiones gubernamentales en las obras de riego (salvo en Sinaloa), los propietarios, en su viada visible al menos desde 1937-1938, extremaron abusos y privilegios para enfrentar de mejor manera los nubarrones que se cernían sobre la economía rural. La Revolución Verde y el auge cerealero y agroindustrial deben ubicarse en este contexto, lo mismo que el elevado desempleo rural y la aparición de diversos movimientos en el campo, encabezados durante un tiempo por la Unión General de Obreros y Campesinos de México y por la Central Campesina

69 Авоites Aguilar, El norte entre algodones, pp. 316-339. 
Independiente, nacida ésta en enero de 1963, en coincidencia con la extinción de la colonización en México.

Hay razones para pensar que la combinación de ese conjunto de tendencias provocó el conflicto en los valles costeros de Sinaloa y Sonora durante la primera mitad de la década de 1970, en particular el conflicto del Valle del Yaqui. ¿Por qué es importante ese conflicto? Entre otras cosas porque la expropiación de 40000 hectáreas de riego en noviembre de 1976 provocó la ruptura de un poderoso grupo de agricultores privados con el Estado mexicano, una ruptura que contrasta con el propósito alemanista encarnado en la CNC.

Ese conflicto norteño está cargado de significados que deben descifrarse. Se refiere al tramo final del siglo xx, cuando se suprimió la reforma agraria, y al inicio del siglo xxi, marcado éste sí por el predominio de la propiedad privada, aunque muy lejos de cualquier idea de colonización. Era innecesaria. Después de la reforma del artículo 27 constitucional de fines de 1991 pudo hacerse legalmente lo que antes se hacía de manera ilegal, es decir, la apropiación y el usufructo de parcelas ejidales. Así, los siglos XIX y xx, entendidos de esta manera, pasaron a formar parte del panteón de la historia, la colonización desde 1963 y la vía ejidal desde 1991. La cuestión sin embargo es más compleja porque el predominio privado del siglo xxI convive con una gigantesca herencia del siglo xx, a saber, que poco más de la mitad del territorio nacional (107 millones de hectáreas) está en manos de ejidos y comunidades agrarias. Contra lo que esperaban sus promotores, la reforma de 1991 apenas ha pellizcado una pequeña porción de esa superficie. ${ }^{70}$

\section{SIGLAS Y REFERENCIAS}

AGN, $P$ Archivo General de la Nación, fondo contemporáneo, Presidentes, Ciudad de México, México.

70 Appendini, “La regularización”, pp. 81-89. 
AGN, MA Archivo General de la Nación, fondo Miguel Alemán, Ciudad de México, México.

AGN, ARC Archivo General de la Nación, fondo Adolfo Ruiz Cortines, Ciudad de México, México.

AGN, ALM Archivo General de la Nación, fondo Adolfo López Mateos, Ciudad de México, México.

AHES Archivo Histórico del Estado de Sinaloa, México.

DDD Diario de los Debates de la Cámara de Diputados.

DDS Diario de los Debates de la Cámara de Senadores.

DOF Diario Oficial de la Federación.

Aboites Aguilar, Luis, Cuentas del reparto agrario norteño 1920-1940, México, Centro de Investigaciones y Estudios Superiores en Antropología Social, 1986 (Cuadernos de Trabajo 186).

Aboites Aguilar, Luis, La irrigación revolucionaria. Historia del Sistema Nacional de Riego del Río Conchos, Chibuabua 1927-1938, México, Secretaría de Educación Pública, Centro de Investigaciones y Estudios Superiores en Antropología Social, 1988.

Авoites Aguilar, Luis, Norte precario. Poblamiento y colonización en México (1760-1940), México, El Colegio de México, Centro de Investigaciones y Estudios Superiores en Antropología Social, 1995.

Aboites Aguilar, Luis, “Optimismo nacional: geografía, ingeniería hidráulica y política en México 1926-1976”, en Mentz (coord.), 2000, pp. 95-152.

Aboites Aguilar, Luis, El norte entre algodones 1930-1970. Poblamiento, trabajo agrícola y optimismo en México, México, El Colegio de México, 2013.

Adams, David B., Las colonias tlaxcaltecas en Coabuila y Nuevo León, Saltillo, Archivo Municipal de Saltillo, 1991.

Aguirre Palancares, Norberto, Ceremonia del cincuentenario de la reforma agraria, Veracruz, Departamento de Asuntos Agrarios y Colonización, 6 de enero de 1965.

Almada, Francisco R., Gobernadores del estado de Chibuabua, México, Imprenta de la H. Cámara de Diputados, 1950.

ApPENDini, Kirsten, "La regularización de la tierra después de 1992: la apropiación 'campesina' de Procede”, en YúnEZ (coord.), 2010, pp. 63-94. 
Astorga Lira, Enrique, Mercado de trabajo rural. La mercancía bumana, México, Era, 1985.

Ballesteros Porta, Juan y Matthew David Edel, Colonización en la cuenca del Papaloapan: una evaluación socioeconómica, México, Centro de Investigaciones Agrarias, 1968.

Berninger, Dieter G., La inmigración en México (1821-1857), México, Secretaría de Educación Pública, 1974, «SepSetentas 144».

Córdova, Arnaldo, La ideología de la Revolución Mexicana. Formación del nuevo régimen, México, Era, 2003.

daAc (Departamento de Asuntos Agrarios y Colonización), Memoria de labores. Septiembre de 1959-agosto de 1960. Presentada por el C. Jefe del Departamento Profr. Roberto Barrios, México, Talleres Gráficos de la Nación, s/p, 1960.

daac (Departamento de Asuntos Agrarios y Colonización), Memoria de labores. Septiembre de 1960-agosto de 1961. Presentada por el C. Jefe del Departamento Profr. Roberto Barrios, México, Talleres Gráficos de la Nación, s/p, 1961.

Domínguez Rascón, Alonso, La politica de reforma agraria en Chibuabua, 1920-1924: sus efectos hasta 1940, México, Instituto Nacional de Antropología e Historia, Plaza y Valdés, 2003.

EHM 2014, Estadísticas históricas de México 2014, Aguascalientes, Instituto Nacional de Geografía y Estadística (versión digital).

Escárcega López, Everardo y Efrén Caraveo Caraveo, Inafectabilidad agraria y pequeña propiedad. Semblanza histórica, México, Centro de Estudios Históricos del Agrarismo Mexicano, 1989.

Fabila, Manuel, Cinco siglos de legislación agraria, 1493-1940, México, Centro de Estudios Históricos del Agrarismo en México, 1981 (edición facsimilar).

FORT, Odile, La colonización ejidal en Quintana Roo: estudios de caso, México, Instituto Nacional Indigenista, 1979.

García MARTínez, Bernardo, "Los poblados de haciendas: personajes olvidados de la historia rural en México", en Cincuenta años de historia de México, México, El Colegio de México, 1991, pp. 331-370. 
García Navarro, Luis, Don José de Gálvez y la Comandancia General de las Provincias Internas del Norte de Nueva España, Sevilla, Escuela de Estudios Hispanoamericanos, 1964.

Gómez Villanueva, Augusto, El campo que yo conocí. La tierra, los hombres, la política. Memorias, México, Sociedad Mexicana de Geografía y Estadística, Miguel Ángel Porrúa, Gobiernos de los estados de Chihuahua y Durango, 2015.

González Navarro, Moisés, La colonización en México, 1877-1910, México, s.e., 1960.

González Navarro, Moisés, La Confederación Nacional Campesina. Un grupo de presión en la reforma agraria mexicana, México, Universidad Nacional Autónoma de México, 1977.

Grammont, Hubert Carton de, Los empresarios agrícolas y el Estado: Sinaloa 1893-1984, México, Universidad Nacional Autónoma de México, 1990.

Hale, Charles, A., El liberalismo mexicano en la época de Mora 1821-1853, México, Siglo Veintiuno editores, 1984.

Ibarrola, Antonio de, Derecho agrario. El campo, base de la patria, México, Porrúa, 1975.

Kourí, Emilio, "Los pueblos y sus tierras en el México porfiriano: un legado inexplorado de Andrés Molina Enríquez”, en Kourí (coord.), 2009, pp. 253330.

Kourí, Emilio (coord.), En busca de Molina Enríquez. Cien años de Los grandes problemas nacionales, México, El Colegio de México, Centro Katz, 2009.

León, Luis L., Crónica del poder en los recuerdos de un político en el México posrevolucionario, México, Fondo de Cultura Económica, 1987.

Ley federal de colonización. Ley que crea la Comisión Nacional de Colonización. Ley reglamentaria del artículo $3^{\circ}$ Constitucional y Ley de riegos, México, Secretaría de Agricultura y Ganadería, 1948.

Leyva Solano, Xóchitl y Gabriel Ascencio Franco (eds.), Colonización, cultura y sociedad, Tuxtla Gutiérrez, Universidad de Ciencias y Artes del Estado de Chiapas, 1997. 
López Serrano, Francisco, Colonización: la conquista de la tierra virgen, como una de las soluciones mejores para el problema campesino: una conferencia, México, Departamento de Asuntos Agrarios y Colonización, 1962.

Martínez Delgado, Gerardo, La experiencia urbana. Aguascalientes y su abasto en el siglo XX, México, Instituto Mora, Universidad Autónoma de Aguascalientes, Universidad de Guanajuato, 2017.

Medin, Tzvi, El sexenio alemanista. Ideología y praxis política de Miguel Alemán, México, Era, 1990.

Mendieta y Núñez, Lucio, El problema agrario de México, México, Porrúa, 1954 ( $6^{a}$ edición, corregida y aumentada).

Mentz, Brígida von (coord.), Identidades, Estado nacional y globalidad. México, siglos XIX y XX, México, Centro de Investigaciones y Estudios Superiores en Antropología Social, 2000.

Moreno Vázquez, José Luis, Por abajo del agua. Sobreexplotación y agotamiento del acuífero de la Costa de Hermosillo, 1945-2005, Hermosillo, El Colegio de Sonora, 2006.

Morton, Ohland, Terán and Texas. A Chapter in Texas-Mexican Relations, Austin, The Texas State Historical Association, 1948.

Navarro García, José, Don José de Gálvez y la Comandancia General de las Provincias Internas del norte de Nueva España, Sevilla, Escuela de Estudios Hispanoamericanos, 1964.

NeLson, Michael, The Development of Tropical Lands: Policy Issues in Latin America, Baltimore y Londres, The Johns Hopkins University Press, 1973.

Nugent, Daniel, Spent Cartidges of Revolution: An Anthropological History of Namiquipa, Chibuahua, Chicago, Chicago University Press, 1993.

Peek, Peter y Guy Standing, "Las políticas de Estado y la migración de la mano de obra", en Peek y Standing (comps.), 1989, pp. 11-45.

Peek, Peter, y Guy Standing (comps.), Políticas de Estado y migración. Estudios sobre América Latina y el Caribe, México, El Colegio de México, 1989.

Poleman, Thomas, The Papaloapan Project. Agricultural Development in the Mexican Tropics, Stanford, University of Stanford Press, 1964. 
Los presidentes de México ante la nación, México, Cámara de Diputados, 1966, 6 volúmenes.

Reyes Osorio, Sergio, Rodolfo Stavenhagen, Salomón Eckstein y Juan BALlesteros, Estructura agraria y desarrollo agrícola en México. Estudio sobre la tenencia y uso de la tierra y el desarrollo agrícola de México, México, Fondo de Cultura Económica, 1979.

Riguzzi, Paolo, "La encrucijada de Baja California Norte, 1882-1890: empresas extranjeras, nacionalismos y relaciones internacionales", en Río y VIDARGAS DEL MORAL (coords.), 2014, pp. 179-214.

Río, Ignacio del y Juan Domingo Vidargas del Moral (coords.), Intereses extranjeros y nacionalismo en el noroeste de México 1840-1920, México, Universidad Nacional Autónoma de México, 2014.

Ruiz Massieu, Mario, Temas de derecho agrario mexicano, México, Universidad Nacional Autónoma de México, 1988.

Samaniego López, Marco Antonio, Ríos internacionales entre México y Estados Unidos. Los tratados de agua de 1906 y 1944, México, El Colegio de México, Universidad Autónoma de Baja California, 2006.

Seis años de política agraria del presidente Adolfo López Mateos, México, Departamento de Asuntos Agrarios y Colonización, 1964.

Silva Herzog, Jesús, El agrarismo mexicano y la reforma agraria. Exposición y crítica, México, Fondo de Cultura Económica, 1974.

Silva Herzog, Jesús, La cuestión de la tierra, México, Centro de Estudios Históricos del Agrarismo en México, 1981, 4 volúmenes.

VON DER BORCH, Maren, "La colonización en la Costa de Hermosillo: una periodización”, en Leyva Solano y Franco (eds.), 1997, pp. 119-128.

Yúnez, Antonio (coord.), Los grandes problemas de México, XI. Economía rural, México, El Colegio de México, 2010. 